\title{
Social network and complementary/alternative medicine use among pregnant women in Ogbia Communities of Rivers and Bayelsa States, Nigeria
}

\author{
Endurance Uzobo ${ }^{1}$, Tolulope Funmilola Ojo ${ }^{2}$, Richard Dele Agbana ${ }^{2}$ \\ \& Adekunle Olayemi Kunle-Olowu ${ }^{2}$ \\ ${ }^{1}$ Department of Sociology, Niger Delta University, Wilberforce Island, \\ Bayelsa State, Nigeria \\ ${ }^{2}$ Department of Community Medicine, College of Medicine and Health Sciences, \\ Afe Babalola University, Ado-Ekiti, Nigeria \\ Email: enduzobo@gmail.com
}

\begin{abstract}
Background: The role of social network in influencing different aspects of health behaviour is a growing aspect of social medicine. However, this issue has not received much attention concerning CAM use. Thus, there are very few studies that have attempted to address the influence of social network on CAM use. Hence, the main objective of this study is to examine the role of social network in Complementary and Alternative Medicine use among pregnant women.

Methods: The study is a cross-sectional study conducted among 36I pregnant women in the Southsouth region of Nigeria, using the questionnaire and in-depth interview, while analysis was done at the univariate, bivariate and multivariate level and thematic content analysis.

Results: Findings from the study showed that, while individual network had a weak influence on the use of CAM, social networks variables jointly predicted the extent of CAM use $\left(\mathrm{R}=0.719, R^{2}=0.517, \mathrm{~F}(5\right.$, $136)=29.162$, Adj. $\left.R^{2}=0.500, p<0.000\right)$. In addition, while family $(\beta=.770, p<0.00 \mathrm{I})$, friends $(\beta=$ $-.688, p<0.000)$, religious organisations $(\beta=.508, p<0.000)$, neighbours $(\beta=-.725, p<0.000)$ as sources of CAM information independently predicted CAM use, co-workers did not.

Conclusion: The study concluded that though individual social network might have minimal influence in the use of CAM, a combination of social network tools could be a potent tool in influencing the complementary and alternative medicine choices of pregnant women. Therefore, health planning and development should consider social networks variables in designing health programmes and policies.
\end{abstract}

Keywords: Social networks, Complementary and alternative medicine, Ogbia, Family, Religious Organization.

\section{Introduction}

Studies have shown that examining individuals' social networks presents a promising avenue for understanding health behaviour. Social network does not only provide emotional and instrumental support around health care (Thoits, 2010). Having strong social network ties and discussing health with social network members have been found to be associated with better recovery from health-related problems (Perry, \& Pescosolido, 20I5), management of chronic health conditions (Vassilev, Rogers, Kennedy, \& Koetsenruijter, 20I4), diagnosis and regulation of hypertensive behaviour of hypertensive conditions (York, \& Waite, 20I2), and a wide variety of other health-related outcomes (Perry, \& Pescosolido, 2010).

These studies could be summarised to mean that people's health-related behaviours and decisions are shaped by the opinions and behaviours of their closest social network contacts. Social network members also serve the function of monitoring health behaviour, ensuring the enforcement of social norms around health practices and decision-making and provide emotional and instrumental support around healthcare utilisation, and aid individuals' sense of personal control over their health (Umberson, Crosnoe, \& Reczek, 2010).

Given the uncertainty surrounding the efficiency of complementary and alternative medicine (CAM) (Mitchell, \& Allen, 2008; Chuntharapat, Petpichetchian, \& Hatthakit, 2008), it is possible that the information-providing and norm-enforcing functions of social networks play an important role in individuals' decisions to experiment with or adopt these forms of treatment. Research has shown that health information-seeking behaviour is the strongest predictor of CAM usage among older adults (Arcury et al., 2013). Balneaves (2008) stated that people 
vigorously draw on health professionals, family, friends, and other social network resources in assessing possible benefits of CAM. O'Connor and White (2009), also found out that concerning norms, people's beliefs around whether or not family and friends support the use of CAM are also predictors of CAM use. Palinkas and Kabongo (2000) in their study showed that CAM usage is primarily attributed to interactions with and referrals from friends and coworkers

These findings suggest that social ties function in several important ways to influence CAM usage, from fostering broad exposure to providing substantial support and recommendations. Research has also shown that having a network that includes non-kin ties is linked with alternative medicine use (Schafer, 2013). In essence, people who have varied sources of social support (e.g. friends, neighbours, and social groups) are more likely to try CAM than people with more kin-centred networks (Shiovitz-Ezra, \& Litwin, 2012). One explanation for this is that people whose networks include different types of ties particularly those outsides of the family have access to a broader range of information and suggestions regarding likely treatment options, in part through discussing health with a wide variety of sources of social support (Goldman, \& Cornwell, 20I5).

It has been proposed that the structure, or wiring, of one's social network, shapes CAM use for reasons alike. Diverse studies in social network analysis show that the acceptance of unusual or innovative ideas and practices hinge on not only the composition of one's network but also the degree to which one's network is structured such that (I) their network ties reach non-redundant (unique) sources of information, and (2) their network members are not so densely interconnected to each other that others are able to control this information and prevent the people in question from using it (Goldman \& Cornwell, 2015). From this point of view, the connection between CAM usage and the variety and range of one's social network may mirror the fact that less diverse networks (e.g., those containing only family members) are more constrained in the sense that their members lean towards adopting similar general, conventional health care practices and collectively reinforce those practices (Goldman, \& Cornwell, 2015).

According to Burt (1992), key factors that link one's social network to CAM usage is the level to which one maintains social ties with people who are not connected. This relational structure is what Burt called network bridging. Bridging is marked by its ability to elicit resources from diverse social domains such as social support and other social benefits. Several reasons have been given for why bridging may be associated with CAM usage. First, being a bridge possibly increases one's chances to learn different health care practices. Having network members who do not know one another increases one's probability of being exposed to different health care choices. Equally, this relational structure increases one's prospect of receiving referrals to different CAM providers. Bridging may also allow individuals to explore alternative treatments under conditions of more relaxed social control and less normative reinforcement of traditional, conventional care than what denser networks might promote (Goldman, \& Cornwell, 2015).

When people are connected to network members who know themselves well, their network members are in a better position to enforce widespread social norms and to informally sanction deviation from those norms (Coleman, 1988). In other words, occupying a bridging position within a social network may make it easier to experiment with unorthodox health practices, as this can occur without concern that one's network members will monitor and sanction that behaviour. Finally, as Cornwell (2009), stated, people who occupy bridging positions also tend to be in a better state of health. Based on this, people who serve as bridges may be more physically able to search out CAM providers, consequently overcoming barriers associated with accessing CAM therapy locations (Jain, \& Astin, 200I).

One pitfall of some of the studies cited above is that they fail to highlight the specific social network influencing the use of CAM, and also none of these studies was conducted in Nigeria. Hence, the import of this study is to examine how specific social network such as family, friends/peers, religious organisation, co-workers and neighbours predict the use of CAM using the South-south region of Nigeria as a case study.

\section{Theoretical framework}

The theoretical foundations of this study are the theories of social network and functional specificity hypothesis. Sociological precursors of the social network theory could be found in the work of Ferdinand Tonnies who stated that social groups could exist as personal and direct social ties that either link individuals who share values and beliefs or impersonal, formal and instrumental social links.

Social network theory is made up of two different sociological perspectives on human interaction (Bernardi, \& Klarner, 20/4). First, according to this theory, social actors are dependent on their structural environment, i.e., on society, on an organisation, or on the network of personal relations in which they are embedded. Second, this structure does not fully determine their actions; instead, it 
provides a framework of opportunities for action, and thus allows for individual agency. This theory states that social structure builds the context of peoples' action, constrains actors in their ability to take actions, shapes actors' interests, and affects how individuals perceive the opportunities to be by taking each of several alternative actions (Bernardi, \& Klarner, 2014). This theory further adds that individuals are embedded in social structures or social networks, which can be perceived as ongoing systems of social relations. The social network theory can be divided into four different sub-theoretical explanations on how social network can influence health behaviours.

The first sub-strand is Social learning theory. According to this theory, Social learning takes place through direct observation or conversation with others. For example, a pregnant woman might learn the use of CAM by watching and talking with family members, friends, co-workers, members of the same religious affiliation and neighbours. According to Bernardi (2003), this is a way of getting information on the significance of a given action.

The next theory, which is the Social pressure theory posits that family and friends affect preferences. This could be in the way of an explicit sanction such as a parent telling their children that they will not receive any assistance if they fail to use a particular CAM therapy. Also, pregnant women might feel compelled to the fact that all their friends are using CAM during pregnancy while they are slowly being left out, feeling out of step with their social group (Scommegna, 2014). This will put them in a subtle pressure to use CAM to either meet up their parents' expectation or meet up with their social group.

Social support theory describes the material or psychological resources an actor can mobilise from friends and family. For instance, using CAM might often attract some physical and psychological benefits from parents, siblings, or friends. These resources might include but not limited to the following; childcare, emotional encouragement, and in some cases, financial assistance. For example, in Bulgaria as noted by Scommegna (20|4), social support for young couples who give birth includes housing in the grandparents' home until the young couple can afford their place.

Finally, Social contagion theory explains the way behaviour can spread among friends and family. Various researchers have observed that the timing of childbearing within social networks tends to occur in sequence; one after another within a (several years) time frame Bernardi (2003). This theory states that contagion includes a distinct emotional reaction, but also involves the synergy of both social learning and social pressure. Hence, the use of CAM could spread to pregnant women through their friends or family members.

Closely related to the social network theory is the functional specificity hypothesis. The functional specificity hypothesis developed by Cutrona and Russell, (1990), Penning (1990) and Simons (1983) [cited in Perry and Pescosolido, 20I0] posits that individuals engage in goal-directed social interaction to access different types of social resources through personal community networks. According to Wellman (1995), most of our social ties are "boutiques" rather than "general stores," and whether consciously or not we "shop" to obtain goods and services that we need. In other words, people tend to activate a given tie for only one or a few specialised functions rather than relying on one person to fulfil all support needs. A relationship or person may be useful for one kind of task or problem, but not another (Sandefur, \& Laumann, 1998).

In short, the functional specificity hypothesis emphasises the fit between the problem or support need at hand and the skills, information, resources, and accessibility of individual ties embedded within network structures and cultures (Perry and Pescosolido, 2010). People can selectively draw on their diverse network resources, activating ties that are most likely to be useful for a purpose (Perry, \& Pescosolido, 20l0). This selective activation of ties during an acute health crisis represents a potentially essential but primarily overlooked coping mechanism (Wellman, 2000). Despite these, only a few discussions on topics such as health services utilisation, compliance, behaviours, and beliefs have been linked empirically to health outcomes (Abbott, Bettger, Hanlon, \& Hirschman, 2012; Perry, \& Pescosolido, 20I0; Schafer, 2013). However, the extent to which individuals with health problems can secure access - through activation of specific ties but not others - to information, treatment options, or support that facilitate recovery may, in part, explain why social network characteristics matter for wellbeing.

\section{Data and methods}

This study was conducted among $36 \mathrm{I}$ pregnant women (325 Quantitative and 36 Qualitative) in fourteen selected communities in five clans of Ogbia in Bayelsa and Rivers States located in the Southsouth region of Nigeria. These communities were chosen because they possess an abundance of forest resources which the people mainly rely on for their daily health needs. The study adopted both the quantitative and qualitative approach using a crosssectional survey design. 
The study made use of mainly the purposive and snowball sampling technique in its quest to get respondents for the study. First, the study purposely selected communities with maternity centres where several women, who were the respondents, go for antenatal services. The purposive sampling technique was further used to select women who were less than eight months pregnant. This was done in order not to disturb those pregnant women who were very close to giving birth as the matrons of these maternity centres advised. Finally, the snowball sampling technique was used to locate pregnant women who do not attend maternity centres to capture their experience in their natural environment and to physically observe the CAM they were currently using.

Data for this study was collected using the questionnaire and an in-depth interview with the assistance of four female research assistants. While most women in the maternity centres were given the questionnaire to fill, those sampled at home were interviewed. Each pregnant woman was interviewed separately. Before the interviews, participants were informed of the aims and the major themes of the study. The interviews pattern was similar to a conversation, where respondents could respond freely to questions.

In cases where respondents do not have formal education and cannot express themselves adequately using the English language, the interview was conducted in the local dialects of the respondents or the use of pidgin (explain) English, while questionnaires were filled with the help of the research assistants.

On average, the interview with each participant lasted for approximately 45 minutes. While the questionnaires took approximately 20 minutes to complete. The questionnaires were simultaneously filled with the help of the research assistants, while the interview personally conducted by the researcher was going on. Everyone that participated in the study was assigned pseudo names which were used for data analysis. However, the location and occupation of the members interviewed were real if the respondents agree to it.

Data generated from the quantitative instruments were analysed based on three levels: univariate, bivariate and multivariate analysis for the quantitative data using the SPSS. Hence, percentages, tables and charts were used for univariate analysis, chi-square crosstabulations for bivariate and multiple regression for multivariate. Qualitative data, on the other hand, were analysed following the steps outlined by Burnard for thematic content analysis through the aid of the NVivo 10.
To maintain a high ethical standard, this research was presented before the department of sociology research committee of the Niger Delta University who approved the study. Also, the study was approved by the Bayelsa State Health Research Ethics Committee of the Ministry of Health, and ethical clearance certificate granted with approval number: BSHREC/Nol.I/I8/I19. Permission was also sought from the heads of communities of the study area involved according to their gate-keeping policy. Also, verbal approval was given by the matrons of the maternity centres after presenting the approval letter from the department of sociology. After obtaining approval from the gate-keepers, the consent of individual participants was also sought before they were enrolled for the study.

Indicators of social network employed in the study were, Family, Friends/Peers, Neighbours, Coworkers and members of the same religious organisation. The indicators were measured by the average numbers of each social network member that respondents seek CAM advice and information from. Data on the extent of CAM use were measured at the interval-ratio scale. For CAM information and advice, respondents were asked the numbers of times they have received CAM information and advice from members of each of their networks. Thus, the independent variables in the study included; Family, Friends/Peers, Neighbours, Co-workers and the same religious organisation, while the dependent variable includes; Numbers of times CAM information and advice was received.

The multiple regression adopted in the study was used to ascertain the average numbers of members of each social network, socio-demographics of respondents and the level of CAM information and advice sourced for by the respondents. The multiple regression is suitable because the data were collected in the interval-ratio scale of measurements. Still, the multiple regression aided the easy computation of the beta value which shows the degree of influence of each of the independent variable to the dependent variable in the study. From the analysis, three models were generated. The first model, looked at the influence of social networks variables (Family, Friends/Peers, Neighbours, Co-workers and members of the same the religious organisation) on CAM use. Model two illustrates the influence of the social network variables on both

CAM use and information, while model three shows the association between social network variables and socio-demographic variables on CAM information and use.

The use of multiple regression is done in this study as it meets the two basic assumptions for the use of a 
multiple linear regression analysis. Firstly, the dependent variable in this study was measured on a continuous scale (i.e., it is an interval/ratio variable), which is the first assumption that must be meet for the use of multiple regression. Example is extent of CAM use represented by number of pregnancies CAM has been used for, with measurements like; I = none, $2=$ one, $3=$ two, $4=$ three and above. Secondly, in this study, we had two or more independent variables which were either continuous (i.e., an interval/ratio variable) or categorical (i.e., an ordinal or nominal variable). For example; names of sub-clans in Ogbia ( 1 = Oloibiri, $2=$ Agholo [Kolo], 3 = Anyama, 4 = Abureni, 5 = Kugbo), Networks of relationship between CAM users and social networks (Family - yes $=I$, no $=0$, Friends - yes $=I$, no $=0$, Religious organizations - yes $=\mathrm{I}, \mathrm{no}=0$, Co-workers yes $=$ I, no $=0$, Neighbours - yes $=I$, no $=0$ ), Stage of pregnancy $(\mathrm{I}=$ Before pregnancy, $2=$ Ist Trimester, $3=2$ nd Trimester, $4=3 r d$ Trimester, 4 $=$ After pregnancy), Dosage of CAM use when used ( $\mathrm{I}=$ No regular pattern of use, $2=$ One at a time, 3 = Using two or more at a time), and other demographic variables which were measured in either nominal (e.g., Marital status - I = Evermarried, $2=$ Never-married, $3=$ Divorced/separated, $4=$ Cohabitation), ordinal (e.g., Educational level $-1=$ No formal education, $2=$ Primary, 3 = Secondary, $4=$ Tertiary), and interval scale (e.g., Age $-1=15-19,2=20-24,3=25-29$, $4=30-34,5=35-39,6=40-44,7=45-49$ ) [see Table 3.6].

\section{Results}

Socio-demographic characteristics of the respondents by sub-groups
This section describes the following sociodemographic variables; age, marital status, education, religion, type of family, occupation, nature of job, employment type, average income per month, number of pregnancies and household status. The overall mean age was 30.95 , with a standard deviation of 5.640 ranging from 15-44 years. The results of the socio-demographic characteristics of the respondents are presented in Table $\mathrm{I}$.

A third $(32.2 \%)$ of the respondents were in the age range $30-34$ years, followed by $22.8 \%$ and $20 \%$ in the age range $25-29$ and 35-39 years, respectively. The rest of the age distribution is shown in Table $I$. In terms of the marital status of the respondents, table I also found out that more than half of the pregnant women $(5 \mathrm{I} .1 \%)$ have remained married. A significant percentage of pregnant women (33.2\%) stated that they were cohabiting. Only a few of the respondents were either still single (never married) [8.3\%] or divorced/separated $(7.4 \%)$.

More than half $(53.2 \%)$ of the respondents had completed secondary education. Nearly a quarter (24.9\%) had acquired a tertiary education. A tenth ( $10.5 \%)$ had acquired primary education, and about $4 \%$ had no formal education.

The dominant religion was Christianity with $93.7 \%$ of respondents practising it. While eight out of ten $(80.8 \%)$ respondents were in monogamous marriages, $12.3 \%$ were in polygamous marriages.

Finally, only 6.5 per cent of the respondents were from single parents' families. Based on this analysis, we can infer that respondents in the area of study practice more of monogamous marriages. The disparity in monogamous polygynous, and singleparents' unions echoes a gradual decline of polygyny in Nigeria which may be as a result of the incursion of modernisation and globalisation.

Table I: Distribution of respondents by socio-demographic variables and linguistic group $(n=325)$

\begin{tabular}{|l|l|}
\hline Demographic Variables & Total N (\%) \\
\hline Age & $17(5.2 \%)$ \\
$15-19$ & $42(12.9 \%)$ \\
$20-24$ & $74(22.8 \%)$ \\
$25-29$ & $108(32.2)$ \\
$30-34$ & $65(20 \%)$ \\
$35-39$ & $19(5.8 \%)$ \\
$40-44$ & \\
Marital Status & $166(51.1 \%)$ \\
Ever Married & $27(8.3 \%)$ \\
Never Married & $24(7.4 \%)$ \\
Divorced/Sep. & $108(33.2 \%)$ \\
Cohabiting & \\
\hline Education & \\
\hline
\end{tabular}




\begin{tabular}{|c|c|}
\hline $\begin{array}{l}\text { No formal education } \\
\text { Primary education } \\
\text { Secondary education } \\
\text { Technical education } \\
\text { Tertiary education } \\
\end{array}$ & $\begin{array}{l}14(4.3 \%) \\
34(10.5 \%) \\
173(53.2 \%) \\
23(7.1 \%) \\
81(24.9 \%)\end{array}$ \\
\hline $\begin{array}{l}\text { Religion } \\
\text { Christianity } \\
\text { Islam } \\
\text { Traditional Religion }\end{array}$ & $\begin{array}{l}305(93.8 \%) \\
\mid(0.3 \%) \\
19(5.8 \%)\end{array}$ \\
\hline $\begin{array}{l}\text { Types of family } \\
\text { Monogamous } \\
\text { polygamous } \\
\text { Single parenthood }\end{array}$ & $\begin{array}{l}262(80.9 \%) \\
4 I(12.6 \%) \\
22(6.8 \%)\end{array}$ \\
\hline $\begin{array}{l}\text { Occupation } \\
\text { Farming } \\
\text { Fishing } \\
\text { Civil servant } \\
\text { Small scale business } \\
\text { Student } \\
\text { Currently not in any } \\
\text { Others }\end{array}$ & $\begin{array}{l}54(\mid 6.6 \%) \\
22(6.8 \%) \\
43(\mid 3.2 \%) \\
85(26.2 \% \\
47(\mid 14.5 \%) \\
16 .(4.9 \%) \\
58(\mid 7.8 \%)\end{array}$ \\
\hline 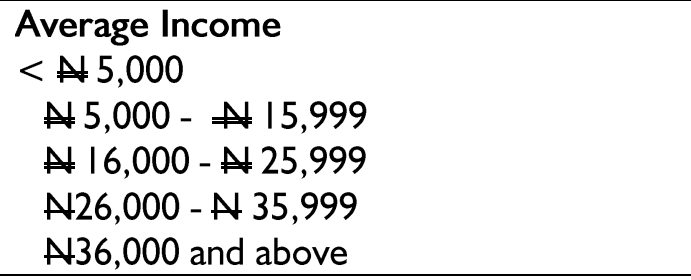 & $\begin{array}{l}58(18.0 \%) \\
107(33.1 \%) \\
57(17.6 \%) \\
31(9.6 \%) \\
72(22.2 \%) \\
\end{array}$ \\
\hline $\begin{array}{l}\text { Number of times pregnant } \\
1 \\
2 \\
3 \\
4 \\
\text { 5and above }\end{array}$ & $\begin{array}{l}105(32.3 \%) \\
63(19.4 \%) \\
40(12.3 \%) \\
69(21.2 \%) \\
48(\mid 4.8 \%)\end{array}$ \\
\hline $\begin{array}{l}\text { Headship status and relationship to head } \\
\text { Head of the house } \\
\text { Proxy to head } \\
\text { Not head of the house } \\
\text { Distant relationship to the head }\end{array}$ & $\begin{array}{l}6(1.9 \%) \\
217(67.4 \%) \\
95(29.5) \\
4(1.2 \%)\end{array}$ \\
\hline
\end{tabular}

Analysis of occupational status shows that the highest proportion (26.2\%) of the respondents were engaged in small-scale businesses. Other occupations mentioned by the respondents include; Farming (I6.6\%), Civil service (I3.1\%), Fishing (6.8\%), Students (14.5\%), not currently in any occupation $(4.9 \%)$ and others (17.8\%).

The average income of respondents showed that those earning between $\$ 5,000-\$ 15,999$ (33.1\%) formed the highest number of respondents. The second highest income earners were those who earn between $\mathrm{A} 36,000$ and above (22.2\%). The other categories of income earners were those that earned less than $\$ 5,000$ (I8.0\%), those that earn between N16,000 - $\$ 25,999$ (17.6\%), and those that earn between N26,000 - N35,999 (9.6\%). The low income earned in the area of study might be attributed to the fact that the respondents are women engaged in low-income occupations like trading and Agricultural activities, coupled with the low level of education.

In respect to the number of times respondents have been pregnant, the analysis shows that a higher number of the respondents (32.3\%) stated that their current pregnancy was the first one. Twelve per cent of the respondents were pregnant for the third time, about a fifth (21.2\%) for the fourth time, and 14.8\% were pregnant at least five times.

Finally, from Table I, the majority of the respondents were proximately related to the head (67.4\%). 29.5 per cent of the respondents stated that they had no relationship whatsoever to the head of the house. 
Only I.9 and I.4 per cent of the respondents were head of their house, and have a distant relationship with the heads of their house, respectively.

\section{Social networks, CAM information and use}

This study examined the influence of social network on CAM information and use. The social network variables comprised of the family, peers/friends, co- workers, religious organisations and members of the same neighbourhood and their composition as sources of CAM information and the influence they have on CAM use. Table 2 shows the report on the number of family members, an approximate number of close friends, the type of information on CAM from social networks as well as specific social networks influencing CAM use.

Table 2: Distribution of respondents by social network and CAM information

\begin{tabular}{|c|c|c|c|c|c|c|c|}
\hline \multirow[b]{2}{*}{ Variables } & \multicolumn{7}{|c|}{ Sub-clans } \\
\hline & $\begin{array}{l}\text { Oloibiri } \\
(n=9 l)\end{array}$ & $\begin{array}{l}\text { Agholo } \\
(n=56)\end{array}$ & $\begin{array}{l}\text { Anyama } \\
(\mathrm{n}=124)\end{array}$ & $\begin{array}{l}\text { Abureni } \\
(\mathrm{n}=26)\end{array}$ & $\begin{array}{l}\text { Kugbo } \\
(n=28)\end{array}$ & $x^{2}$ & $\begin{array}{l}\mathrm{p}- \\
\text { value }\end{array}$ \\
\hline \multicolumn{8}{|c|}{ Number of family members you get CAM information from } \\
\hline $\mathrm{I}-5$ & $82(90.1)$ & $44(81.5)$ & $99(79.8)$ & $2(7.7)$ & $24(92.3)$ & \multirow{4}{*}{179.199} & \multirow{4}{*}{0.000} \\
\hline $6-10$ & $6(6.6)$ & $7(13.0)$ & $15(12.1)$ & $2(7.7)$ & $\mathrm{I}(3.8)$ & & \\
\hline $11-15$ & - & $2(3.7)$ & $3(2.4)$ & - & $\mathrm{I}(3.8)$ & & \\
\hline 16 and above & $3(3.3)$ & $\mathrm{I}(\mathrm{I} .9)$ & $7(5.6)$ & $22(84.6)$ & - & & \\
\hline \multicolumn{8}{|c|}{ Approximate number of close friends you get CAM information from } \\
\hline $\mathrm{I}-5$ & $52(81.2)$ & $50(94.7)$ & $105(84.7)$ & $4(15.4)$ & $20(74.1)$ & \multirow{4}{*}{261.766} & \multirow{4}{*}{0.000} \\
\hline $6-10$ & $2(3.1)$ & I (I.9) & $19(15.3)$ & - & $7(25.9)$ & & \\
\hline $11-15$ & $8(12.5)$ & $2(3.8)$ & - & - & - & & \\
\hline 16 and above & $2(3.1)$ & - & - & $22(84.6)$ & - & & \\
\hline \multicolumn{8}{|c|}{ Type of CAM-related information from social networks } \\
\hline Where to get CAM & $40(44.0)$ & $47(83.92)$ & $91(73.38)$ & $2(0.08)$ & $18(64.3)$ & \multirow{5}{*}{256.821} & \multirow{5}{*}{0.000} \\
\hline When to use CAM & $45(49.45)$ & $33(58.92)$ & $74(59.68)$ & $21(80.77)$ & - & & \\
\hline How to use CAM & $48(50.75)$ & $33(58.92)$ & $76(6 \mid .29)$ & $2(8.0)$ & $20(71.4)$ & & \\
\hline Benefit of CAM & $35(38.46)$ & $34(60.7 I)$ & $79(63.70)$ & $15(57.69)$ & - & & \\
\hline Risk of CAM use & $17(28.68)$ & $52(92.86)$ & $2(0.02)$ & $5(0.19)$ & $9(32.1)$ & & \\
\hline \multicolumn{8}{|c|}{ Specific Social network influencing CAM use } \\
\hline Family & $52(94.5)$ & $41(83.7)$ & $91(92.9)$ & - & $23(92.0)$ & \multirow{5}{*}{90.913} & \multirow{5}{*}{0.000} \\
\hline Friends & $3(5.5)$ & $4(8.2)$ & $5(5.1)$ & - & - & & \\
\hline $\begin{array}{l}\text { Religious } \\
\text { organisation }\end{array}$ & - & - & - & - & $\mathrm{I}(4.0)$ & & \\
\hline Co-worker & - & - & - & - & - & & \\
\hline Neighbours & - & I (2.0) & $2(100.0)$ & $2(100.0)$ & I (4.0) & & \\
\hline
\end{tabular}

However, when respondents were asked the number of members that constituted their respective families, the table showed that more than half of the respondents indicated that they had between I-5 members in their respective families as depicted by Oloibiri (90.1\%), Agholo (81.5\%), Anyama (79.8\%) and Kugbo $(92.3 \%)$. While the majority of respondents had between $\mathrm{I}$ and 5 members in the sub-clans aforementioned, the majority of respondents in Abureni (84.6\%) had 16 and above members. As a matter of fact, there is significant relationship between family composition and subclans $\left(x^{2}=179.199, \mathrm{p}<0.000\right)$.

Friendships, as part of social networks, have a significant association with sub-clans $\left(x^{2}=261.766\right.$, $\mathrm{p}<0.000$ ). While majority of the respondents had between Iand 5 friends as revealed by Oloibiri (81.2\%), Agholo (94.7\%), Anyama (84.7\%) and Kugbo (74.1\%), more than half of respondents from Abureni $(84.6 \%)$ had 16 and more friends.

In fact, the CAM information received from the various social networks highlighted was ascertained from the respondents. It was revealed that most of the respondents from Agholo (83.9\%), Anyama $(73.4 \%)$, and Kugbo (64.3\%) indicated that the significant CAM information they got from their social network was 'where to get CAM'. Equally, a more significant number of the respondents from Agholo (58.9\%), Anyama (59.7\%) and Abureni (80.1\%) said they received information about 'when to use CAM' in pregnancy from their social network. 
Further information about CAM shows that majority of the respondents except for Abureni (8.0\%)

Indicated that the CAM information they got from their social networks was about 'how to use CAM' in pregnancy including 'benefits of CAM', while the highest percentage of respondents from Agholo (92.7\%) signified that information about 'risks of CAM use' was received from their respective social networks. This implies that information about where, when and how to use CAM is fundamental to the extent of CAM use. It also means that the information varies significantly by sub-clans.

Additionally, the specific social networks influencing CAM information among the study population were examined. The table reveals that a more significant number of the respondents in all sub-clans except Abureni indicated 'family' (as represented by Oloibiri $94.5 \%$, Agholo $83.7 \%$, and Anyama $73.4 \%$ ) as the significant network influencing CAM use, while other forms of social networks such as the peers/friends, religious organisations, coworkers, and neighbours had small proportions of respondents. This suggests that family social network is more influential in sharing CAM information when compared to other social networks.

A multiple regression analysis predicting social networks on CAM information and use

The need to examine the predictive influence of each social network in collaboration with confounding variables on CAM information and use necessitated the use of multiple regressions. Using multiple regression analysis, Table 3 presents the summary of the predictive influence of social network variables on

the extent of CAM use by pregnant women as represented in model I, II, and III, respectively. This was necessitated by the need to understand the complexities of the predictive influence of social network and confounding variables on the extent of CAM use in Ogbia communities. As the table shows, there are significant influences between predictor and dependent variables, which suggest that the explanatory variables significantly explained the dependent variable at higher percentages.

As revealed in model I, the social network variables significantly predicted the extent of CAM use $(R=0.719,=0.517, F(5,136)=29.162$, Adj. $=0.500, p<0.000)$. While family friends and coworkers did not independently influence the extent of CAM use, religious organisations $(\beta=-.793$, $\mathrm{p}<0.000)$ and neighbours $(\beta=0.305, \mathrm{p}<0.012)$ as social networks significantly influenced the use of CAM.

In model II, the combination of both social network variables and sources of CAM information received significantly predicted CAM use $(R=0.845$, $=0.713, \mathrm{~F}(10,|3|)=32.622$, Adj. $=0.692$, $\mathrm{p}<0.000)$. This result reveals that the percentage increase in the joint influence of the predictor variables on the dependent variable from model I to II is $20.0 \%$. Although family, friends, co-workers, neighbours as social network variables did not predict the extent of CAM use, religious organisation as a social network independently predicted CAM use $(\beta$ $=\quad-.543, \quad \mathrm{p}<0.000)$.

Table 3: Multiple regression showing the influence of social networks on CAM use and information

\begin{tabular}{|c|c|c|c|c|c|c|c|c|c|}
\hline Model & Predictor Variables & F-Ratio & $\begin{array}{l}\text { Sig. of } \\
\mathrm{P}\end{array}$ & $\mathbf{R}$ & $\mathbf{R}^{2}$ & Adj. $R^{2}$ & $\beta$ & $\mathrm{T}$ & $\mathbf{P}$ \\
\hline I & $\begin{array}{l}\text { Family } \\
\text { Friends } \\
\text { Religious organizations } \\
\text { Co-workers } \\
\text { Neighbours } \\
\end{array}$ & 29.162 & 0.000 & .719 & .517 & .500 & $\begin{array}{l}-.059 \\
-.146 \\
-.793 \\
.034 \\
.305 \\
\end{array}$ & $\begin{array}{l}-.499 \\
-1.176 \\
-7.540 \\
.454 \\
2.538 \\
\end{array}$ & $\begin{array}{l}.618 \\
.242 \\
.000 \\
.651 \\
.012\end{array}$ \\
\hline II & $\begin{array}{l}\text { Family } \\
\text { Friends } \\
\text { Religious organizations } \\
\text { Co-workers } \\
\text { Neighbours } \\
\text { Family } \\
\text { Friends } \\
\text { Religious organizations } \\
\text { Co-workers } \\
\text { Neighbours }\end{array}$ & 32.622 & 0.000 & .845 & .713 & .692 & $\begin{array}{l}.201 \\
.049 \\
-.543 \\
.057 \\
.007 \\
.275 \\
.214 \\
.483 \\
.213 \\
-.620 \\
\end{array}$ & $\begin{array}{l}.729 \\
.479 \\
-5.450 \\
.550 \\
.069 \\
1.373 \\
-1.118 \\
4.027 \\
2.033 \\
-4.922 \\
\end{array}$ & $\begin{array}{l}.086 \\
.633 \\
.000 \\
.583 \\
.945 \\
.172 \\
.265 \\
.000 \\
.044 \\
.000 \\
\end{array}$ \\
\hline III & $\begin{array}{l}\text { Family } \\
\text { Friends } \\
\text { Religious organizations }\end{array}$ & 29.619 & 0.000 & .920 & .846 & .817 & $\begin{array}{l}.404 \\
.053 \\
-.882 \\
\end{array}$ & $\begin{array}{l}3.212 \\
.569 \\
-6.554\end{array}$ & $\begin{array}{l}.002 \\
.570 \\
.000 \\
\end{array}$ \\
\hline
\end{tabular}




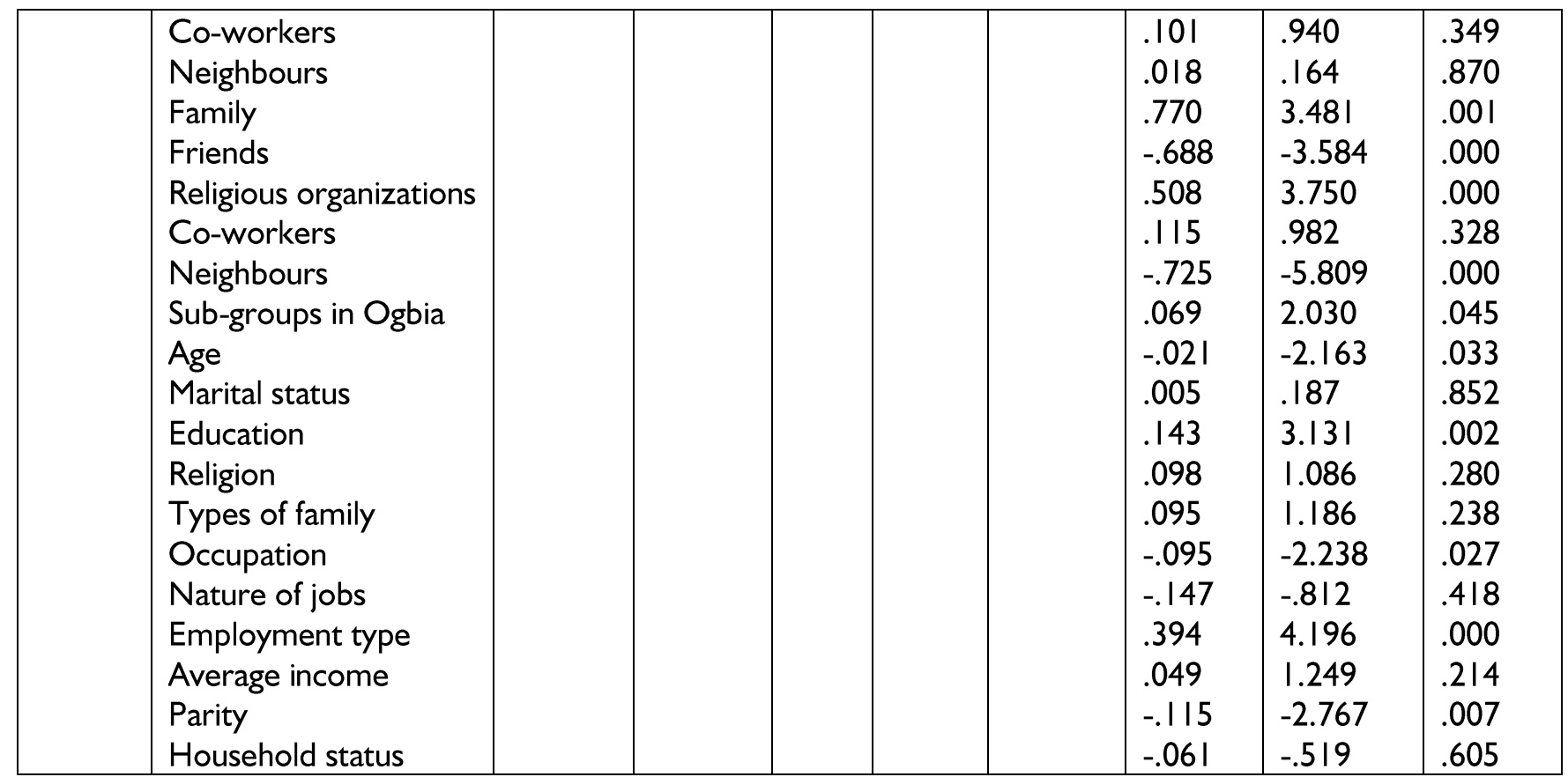

Likewise, religious organisation as source of CAM information $(\beta=.483, p<0.000)$, co-workers $(\beta=$ $.213, p<0.044)$, and neighbours $(\beta=-.620$, $\mathrm{p}<0.000)$ predicted the extent of CAM use, while family and friends as sources of CAM information did not. Based on this result, we can deduce that the sources of CAM information and social networks cannot be separated from the predictive influence of CAM use. This is because there is a likelihood that the information that leads to the use of CAM and perhaps the actual provision of CAM ingredients is from the same sources.

Model III further shows the analysis of the joint influence of social network, sources of CAM information and socio-demographic variables. The summary of the result reveals that there is significant relationship between predictor and dependent variables $\left(\mathrm{R}=0.920, R^{2}=0.846, \mathrm{~F}_{(22,119)}=28.80\right.$, Adj. $\left.R^{2}=0.817, \mathrm{p}<0.000\right)$. It shows that there is an increase in the percentage contribution to the dependent variables by $13.3 \%$ from model II to III. The independent predictive influences of the family $(\beta=.404, p<0.002)$, religious organisation $(\beta=-$ $.882, p<0.000)$ as social network variables are significantly related to the use of CAM, while friends, co-workers and neighbours are not.

In addition, while family $(\beta=.770, p<0.001)$, friends $(\beta=-.688, p<0.000)$, religious organisations $(\beta=.508, p<0.000)$, neighbours $(\beta=-.725$, $p<0.000$ ) as sources of CAM information significantly predicted CAM use, co-workers did not. In fact, subgroups in Ogbia $(\beta=.069, p<0.045)$, age $(\beta=-$ $.021, p<0.033)$, education $(\beta=.143, p<0.002)$, occupation $(\beta=-.095, p<0.027)$, employment type $(\beta=.394, p<0.000)$, parity $(\beta=-.115, p<0.007)$ as socio-demographic variables significantly predicted http://aps.journals.ac.za
CAM use, while marital status, religion, types of family, nature of jobs and average income did not determine the extent of CAM use. This indicates that the addition of socio-demographic variables largely influenced the use of CAM among pregnant women.

To buttress the findings from the quantitative analysis, that family members, friends and religious associates greatly influenced CAM information and its use among pregnant women, a participant from Otuoke explained thus:

'My family members greatly influence my use of CAM. This is because my mother advised me to go for massaging, take herbs (which she gave me) and $I$ accepted because she has given birth to 15 children all using CAM and had no side effects. My friend that advised me to use hydraulics on my skin to ease the rash and I accepted. Also, my religious organisations influence my use of CAM because if a church member tells me that pregnant women are asked to go to church for prayers, I follow the person' (IDI/Otuoke/Oloibiri/20I8).

From the perspective of another participant from Kolo, it was specifically reported that mother, sisters and the father of her baby were the social networks that influenced her use of any form of medicine either CAM or conventional medicine. As she opined:

'My mother, sisters and the father of my baby greatly influence my use of CAM or conventional care. This is because if they tell me that it is time to take my drugs, go to church or the hospital, I usually listen' (IDI/Kolo/Agholo Clan/2018).

Similar to the report above, a participant from Otuasega also stated that: 
'The members of my social network that influence my use of CAM a lot are my mother, my friend and the father of my child. They (especially my mum and friend) usually remind me to go and massage as well as prepare the local herbs for me. Sometimes my mum follows me to the woman that massage and she also goes to the bush to get the herbs for me' (IDI/Otuasega/Agholo Clan/2018).

\section{Another participant also narrated that:}

'My social network-my mother, sisters, aunt, friends and neighbours usually give me an advice concerning my pregnancy and I listen to them. My mother usually gets the herbs for me when coming from the farm and personally prepares it for me. The members of my social network that influenced my use of CAM is my mother. She encouraged me to go for massaging as well as continue taking the Agu herbs' (IDI/Otuakeme/Oloibiri Clan/20I8).

A participant from Otuokpoti community also explained that:

'The social network that has influenced my use of CAM are my friends, neighbours and family friends. My friend introduced me to alligator pepper and bitter kola, my neighbours told me about the honey, while my family members (elder sisters and Mother) informed me about the unripe fruits' (IDI/Otuokpoti/Anyama Clan/2018).

This by implication suggests that social networks significantly influence CAM information as well as the use of CAM. Most of the information received could also lead to the direction of the sources of CAM ingredients, the direction of use of CAM including its side effects among others. This follows that social networks perform both positive and negative functions on the use of CAM among pregnant women.

\section{Discussion of findings}

The research found out that social network plays a significant role in the distribution of CAM information and use in the five clans studied. It was discovered that majority of the respondents in the five clans were informed about CAM by family members. Oloibiri had $94.5 \%$, Anyama had $92.9 \%$, Kugbo (Kolo) had $92.0 \%$, and Agholo had $83.7 \%$ of respondents agreeing that they got information about CAM from family members. This finding is in line with the studies of Dabaghian et al, (2012), Hashim et al, (2005) and Khadivzadeh and Ghabal (2012) that all respectively had $60.2 \%, 65 \%$, and $33.5 \%$ of their respondents agreeing to the fact that they got information about CAM from family/friends.

Also, as revealed in this study, social network variables significantly predicted the extent of CAM use. While family friends and co-workers did not independently influence the extent of CAM use, religious organisations and neighbours as social network significantly influenced the use of CAM. Different studies have also corroborated this position that religious affiliation is associated with different aspect reproductive health (Solankea, Oladosu, Akinlo \& Olanisebe, 20I5; Chiswick \& Mirtcheva, 2010; Odimegwu, 2005).

Again, this study can be compared to the study of Tabatabaee (20I I) who indicated that $87.3 \%$ family members, and $12.6 \%$ of other social networks (friends, midwives, neighbours, Primary health care providers) influenced the use of traditional medicine. Still, this finding is also corresponding to Smith (20 I I) study who stated that social networks play a role in reproductive behaviour across rural-urban boundaries. Smith concluded in his study that networks of home people, especially kinspeople, provide access to the opportunities and resources which is vital in explaining the continued value of high fertility. Other studies such as Dabaghian et al., (20/2), and Sawalha (2007) similarly confirmed this assertion.

Additionally, the findings from this study confirm that of Adedini (2014) who found out that neighbourhood characteristics are associated with health outcome such as under-five mortality in Nigeria. For instance, Adedini findings showed that being born or raised in poor neighbourhoods was associated with elevated hazards of death before age 5. A previous study by Antai (20I I) also had earlier established the association between residence and under-five mortality in Nigeria, where his findings showed that the while characteristics of the neighbourhood characteristics alleviate under-five mortality risks in South-west Nigeria, community characteristics tend to exacerbate risks of under-five mortality in other regions, especially North-east, North-west and South-south.

\section{Conclusion}

Social network is a powerful tool in influencing the health choices of people. Based on the results of this study, the following conclusions could be made: Firstly, social networks variables jointly influence the extent of CAM use among pregnant women in the study area. The family and religious organisations are the most important social network variables that influence the use of CAM and provide CAM information among pregnant women in the region. Furthermore, this study concluded that the type of 
CAM information provided by social network also determines the extent of CAM use among pregnant women. Hence, religious organisation, co-workers, and neighbours as a source of CAM information for pregnant women independently predicted the extent of CAM use. Additionally, age, education, occupation, employment type, and parity as socio-demographic variables significantly predicted CAM use.

The existence of social network effects on health provides a strong theoretical and practical backing in the field of social medicine. In essence, health consequences in people no longer rely on their actions alone, but also on the actions of those around them; therefore, collective and not just individual interventions become expedient. Hence, the existence of social networks means that people and events are interdependent and that health and health care can transcend the individual in ways that patients, doctors, policymakers, and researchers should care about. Therefore, health planning and development should consider these social networks when designing health programmes and policies. For instance, health initiatives like that of the save one million lives initiatives could be sold to powerful network of pregnant women, who in turn might influence the use of the programme in the long run.

\section{Acknowledgement}

We want to acknowledge the contributions made by some senior colleagues: Prof. Edet M. Abasiekong and $\operatorname{Dr}$ Elliot A. Sibiri who edited this work and made useful suggestions to improve the status of this work. We also wish to appreciate the contributions of some research assistants recruited from the research locale to help in the collection of data namely; Miss Amakuro Nadiquan Doris, Miss Brightest Bright Inemugha, Miss Godswill Dumomaziba and Miss Johnson Elizabeth.

\section{References}

Abbott, K. M., Bettger, J. P., Hanlon, A., \& Hirschman, K. B. 2012. "Factors Associated with Health Discussion Network Size and Composition Among Elderly Recipients of Long-Term Services and Supports". Health Communication, 27(8), 784-793.

Adedini, S.A. 2014. "Neighbourhood characteristics and under-five mortality in Nigeria". African Population Studies 27, (2 Supp): 273-283.

Antai, D. 20II. "Regional inequalities in under-5 mortality in Nigeria: a population-based analysis of individual-and community-level determinants". Population Health Metrics 9, (6): I-27.

Arcury, T.A., Nguyen, H.T., Sandberg, J.C., Neiberg, R.H., Altizer, K.P, Bell., R.A., and Quandt, S.A. 2013. "Use of Complementary Therapies for
Health Promotion Among Older Adults". Journal of Applied Gerontology. doi: I0.I 17.

Balneaves, L.G. 2008. "Patient Decision-Making about Complementary and Alternative Medicine (CAM) in Cancer Management: The Context and Process". Current Oncology, 15, 24-30.

Bernardi, L. 2003. "Channels of Social Influence on Reproduction". Population Research and Policy Review, 22(5), 427-555.

Bernardi, L., and Klarner, A. 2014. "Social Networks and Fertility". Demographic Research, 30 (I), 64I-670.

Burt, R. 1992. "Structural holes: The social structure of competition". Cambridge: Harvard University Press.

Chiswick, B. R., and Mirtcheva, D. M. 20I0. "Religion and Child Health". Discussion Paper No, 52/5

Chuntharapat, S., Petpichetchian, W., \& Hatthakit, U. 2008. Yoga During Pregnancy. Effects on Maternal Comfort, Labour Pain and Birth Outcomes. Complementary Therapies in Clinical Practice, 14, 105-II5.

Coleman, J.S. 1988. "Social Capital in the Creation of Human Capital". American Journal of Sociology, 94:S95-SI 20.

Cornwell, B. 2009. "Network bridging potential in later life: life-course experiences and social network position". Journal of Aging and Health, 21 (I), 129-54.

Cutrona, C.E., and Russell, D. 1990. "Type of social support and specific stress: toward a theory of optimal matching”. In: Sarason, I., Sarason, B., \& Pierce, G., eds. Social support: An interactional view. New York: Wiley and Sons.

Dabaghian, F.H., Fard, M.A., Shojaei, A., Kianbakht, S., Zafarghandi, N., and Goushegir, A. 20I2. "Use and Attitude on Herbal Medicine in a Group of Pregnant Woman in Tehran". I Med Plants, I I (4I), 22-33.

Goldman, A., and Cornwell, B. 2015. "Social Network Bridging Potential and the Use of Complementary and Alternative Medicine in Later Life". Soc Sci Med., I40, 69-80.

Hashim, M., Johina, A., Deyaa, K., Fareeda, M., Mohamed, H., and Faten, A. 2005. "Knowledge attitude and practice of complementary and alternative medicine (CAM) among pregnant women: a preliminary survey in Qatar". Middle East J Fam Med., 7(10), 6-I4.

Jain, N., and Astin, J.A. 200I. "Barriers to acceptance: an exploratory study of complementary/alternative medicine disuse". Journal of Alternative and Complementary Medicine, 7(6):689-96.

Khadivzadeh, T., and Ghabel, M. 2012 "Complementary and alternative medicine use in 
pregnancy in Mashhad, Iran". Iran J Nurs Midwifery Res May, I7(4), 263-269.

Mitchell, M., and Alen, K. 2008. An Exploratory Study of Women's Experiences and Key Stake Holders' View of Moxibustion for Cephalic Version in Breech Presentation. Complementary Therapies in Clinical Practice, I4, 264-272.

O'Connor, E.L, and White, K.M 2009. "Intentions and Willingness to use Complementary and Alternative Medicines: What Potential Patients Believe about CAMs". Complementary Therapies in Clinical Practice. I5(3): I 36-40.

Odimegwu, C. 2005. "Influence of Religion on adolescent sexual attitudes and behaviour among Nigerian University Students: Affiliation or Commitment?" African Journal of Reproductive Health 9(2): I25-| 40.

Palinkas, L.A., and Kabongo, M.L. 2000. "The use of complementary and alternative medicine by primary care patients: A SURF*NET study". The Journal of Family Practice, 49(I2), II II-30.

Perry, B.L, and Pescosolido, B.A. 2010 "Functional specificity in discussion networks: The influence of general and problem-specific networks on health outcomes". Social Networks, 32(4), 345-357.

Perry, B.L., and Pescosolido, B.A. 20I5. "Social network activation: The role of health discussion partners in recovery from mental illness". Social Science \& Medicine, 125, I | 6-28.

Sandefur, R. L., and Laumann, E. O. 1998. "A Paradigm for Social Capital". Rationality and Society, I0(4), 48I-50I.

Sawalha, A.F. 2007. "Consumption of Prescription and non-Prescription Medications by Pregnant Women: A Cross Sectional Study in Palestine". Islam Univ J. I5(2):4 I-57.
Schafer, M.H. 2013. "Discussion networks, physician visits, and non-conventional medicine: probing the relational correlates of health care utilization". Social Science \& Medicine, 87: I76-184.

Scommegna, P. 2014. "Family, Friends Help Shape Childbearing Choices". Population Reference Bureau

Shiovitz-Ezra, S., and Litwin, H. 20/2. "Social network type and Health-related Behaviours: Evidence from an American National Survey". Soc. Sci. \& Medicine, 75(5):90I-4.

Smith, D.J. 20II. "Rural-to-urban migration, kinship networks, and fertility among the lgbo in Nigeria". African Population Studies 25, (2):320-336

Solanke, B.L., Oladosu, O.A., Akinlo, A., and Olanisebe, S.O. 2015. "Religion as a Social Determinant of Maternal Health Care Service Utilisation in Nigeria". African Population Studies, 29(2); |868-|88|.

Tabatabaee, M. 20II. "Use of herbal medicine among pregnant women referring to Valiasr Hospital in Kazeroon, Fars, South of Iran”. J. Med Plants, I0(37):96- 108.

Thoits, P.A. 20I0. "Stress and health: major findings and policy implications". Journal of Health and Social Behavior, 5I(I), 4I-53.

Umberson D, Crosnoe R, and Reczek C. 2010. "Social Relationships and Health Behavior Across Life Course". Annual Review of Sociology. 36, I39-157.

Vassilev, I., Rogers, A., Kennedy, A., and Koetsenruijter, J. 2014. "The influence of social networks on self-management support: A meta synthesis". BMC Public Health, |4(1):7|9. 